\title{
The Impact of a Microbial Sealant to Reduce Surgical Site Infections in High Risk Cardiac Surgery Patients
}

\author{
Dohmen PM ${ }^{1 *}$, Gabbieri D1, Weymann $A^{1}$, Linneweber $\mathrm{J}^{1}$, Geyer $\mathrm{T}^{2}$ and Konertz W'
}

${ }^{1}$ Department of Cardiovascular Surgery, Charité Hospital, Medical University, Berlin

${ }^{2}$ Department of Anesthesiology, Charite Hospital, Medical University Berlin, Berlin, Germany

\begin{abstract}
Introduction: Post-sternotomy infection is a serious cause for morbidity and mortality after cardiac surgery. The goal of this study was to evaluate the impact of a microbial sealant on post-sternotomy infections in high risk patients undergoing cardiac surgery.

Methods: Between January 2006 and July 2008 a total of 291 consecutive patients underwent cardiac surgery with a Fowler score of at least 10, which indicates high risk patients to develop surgical site infection (SSI). Patients were divided into a control group $(n=132)$ receiving standard institutional preoperative care and a microbial sealant group $(n=159)$ received additionally a microbial skin sealant. Pre- and peri-operative characteristics were examined for both groups. The clinical end-point of this study was freedom of post-sternotomy infection.

Results: Follow up was $100 \%$ completed. The preoperative risk score of the control and the microbial sealant group were similar, respectively $15.5 \pm 4.0$ and $15.2 \pm 3.8(p=0.513)$. Comparing pre- and peri-operative characteristics of both groups, significant higher rates of carotid artery disease $(p=0.022)$ and diabetics $(p=0.046)$ were found in the microbial sealant group. All other pre- and peri-operative characteristics were similar for both groups. The clinical end-point however, showed a significant decrease of SSI in the microbial sealant group $2.5 \%$ $(n=4)$ versus the control group $7.6 \%(n=10),(p=0.045)$.

Conclusions: This study showed that the additional use of a microbial sealant to standard institutional preoperative preparation reduces statistically significant the risk for surgical site infection in high risk patients undergoing cardiac surgery.
\end{abstract}

Keywords: Surgical site infection; Cardiac surgery; Microbial skin sealant; Infection prevention

\section{Introduction}

Surgical site infection (SSI) is a serious complication after cardiac surgery. The frequency of post-sternotomy infection range between $2 \%$ and $15 \%$, associated with increased morbidity and mortality $[1,2]$. Mortality rates in patients infected with methicillin-resistant Staphylococcus aureus (MRSA) are as high as 74\% [3]. Mekonto-Dessap et al. [4] examined the mortality rate of patients with post-sternotomy mediastinitis, at 30 days postoperatively, by MRSA and MethicillinSusceptible Staphylococcus aureus respectively, 40\% and 15\% [4]. In 41 patients reassessed 3 years after surgical treatment, the mortality rates were $74 \%$ and $21 \%$ respectively. In addition to the destructive impact on individual patients, there is a potential financial impact on treating SSI starting from superficial wound infection, and major mediastinitis can even double the total cost for surgery [5].

Generally an intact skin withstand microbial invasion by cellmediated immunity as well as antibodies and therefore microorganisms cannot past the keratinized layers of the epidermis. In addition, the relative dryness of the skin limits growth of the "normal" skin flora [6]. There is a complex ecosystem between the microbes, presented on the skin or within the human body, and the total number of host cells. The microbes however far extend the number of host cells. Microorganisms that constitute the normal skin flora include, in addition to Staphyloccus aureus and coagulase-negative staphylococci (CoNS) chiefly Staphylococcus epidermidis--Propionibacterium acnes, gramnegative bacilli, micrococci, and Corynebacterium spp [7]. Microbial sealant can decrease the penetration of bacteria into the surgical site during surgery which was proven in several previous studies [8-10].
This study evaluates the effects and contribution of a microbial sealant on high risk patients for SSI after cardiac surgery.

\section{Patients and Methods}

\section{Patient selection}

High risk patients for SSI in cardiac surgery are patients suffering from obesity (body mass index $>30$ ), diabetes, age, re-operation, chronic obstructive pulmonary disease, emergency surgery, peripheral or cerebral vessel disease, hypertension, hypercholesterolemia, renal impairment, immunosuppressive treatment, congestive heart failure, cardiogenic shock, decrease left ventricular ejection fraction $(\mathrm{EF}<40 \%)$ [11-17] these clinical predictors for SSI are incorporated in the Fowler score [18], which was initially used for coronary bypass patients. High risk patients were identified as patients with a score above 10 which would predict a probability having a SSI of $3.1 \%$.

A total of 291 adult patients were identified on high risk for SSI

*Corresponding author: Dohmen PM, M.D, Ph.D., Department of Cardiac Surgery, Heart Centre Leipzig, University of Leipzig, Struempellstrasse 39, D-04289 Leipzig, Germany, Tel: +49-341-865-1422; Fax: +49-341-865-1452 E-mail: pascal.dohmen@yahoo.de

Received March 04, 2013; Accepted April 02, 2013; Published April 17, 2013

Citation: Dohmen PM, Gabbieri D, Weymann A, Linneweber J, Geyer T, et al. (2013) The Impact of a Microbial Sealant to Reduce Surgical Site Infections in High Risk Cardiac Surgery Patients. J Medical Microbiol Diagnosis S4: 002. doi:10.4172/2161-0703.S4-002

Copyright: (c) 2013 Dohmen PM, et al. This is an open-access article distributed under the terms of the Creative Commons Attribution License, which permits unrestricted use, distribution, and reproduction in any medium, provided the original author and source are credited. 
undergoing on-pump cardiac surgery from January 2006 till July 2008 at the Department of Cardiovascular Surgery of the Charity Hospital, by a single surgeon (PMD). Standard institutional preoperative care was performed in 132 patients (control group) and 159 patients (microbial sealant group) received additionally InteguSeal ${ }^{\circledR}$ (Kimberly Clark Health Care, Atlanta, Georgia, USA).

SSI were registered and recorded at the German Nosocomial Infection Surveillance System (Krankenhaus Infections Surveillance System, KISS) [19]. The participation on this surveillance was approved by the Institutional Board on the Ethics of Clinical Studies. All data were de-identified and accorded to patient pre-, peri- and postoperative data. Pre-operative preparation was standardized [7], as well as peri-operative management was performed as published in the past [20].

\section{Clinical endpoint}

This clinical study end-point was freedom of superficial or deep SSI in accordance with the Centers for Disease Control and Prevention [21]. Superficial SSI was defined as treated with or without vacuum assisted closure (VAC) therapy with closed sternum before discharge and/or readmission within 30 days of surgery. Infection was documented by at least one of the following: 1) purulent drainage, with or without laboratory confirmation, from the superficial incision; 2) organisms isolated from an aseptically obtained culture of fluid or tissue from the superficial incision; 3 ) at least one of the following signs of symptoms of infection: pain or tenderness, localized swelling, redness, or heat and superficial incision is deliberately opened by surgeon, unless incision is culture-negative; or 4) diagnosis of superficial incision SSI by the surgeon or attending physician. Deep SSI/mediastinitis was defined as infection of the surgical site treated with VAC therapy before discharge and/or readmission within 30 days of surgery if no implant is left in place or within one year if implant is in place and the infection appears to be related to the operation. Infection was documented by at least one of the following: 1) purulent drainage from a drain that is placed through a stab wound into the organ/space; 2) organisms isolated from an aseptically obtained culture of fluid or tissue in the organ/ space; 3) an abscess or other evidence of infection involving the organ/ space that is found on direct examination, during reoperation, or by histopathology or radiologic examination; or 4) diagnosis of organ/ space SSI by the surgeon or attending physician.

\section{Statistical Analysis}

Data were analyzed using SPSS software (version 13.0; SPSS, Inc., Chicago, IL, USA). Categorical variables were analyzed using Chisquare. Continuous variables were analyzed with Student's t test. A $p$-value of less than 0.05 was considered to be significant on two-tailed testing.

\section{Results}

\section{Patient selection}

The pre-operative SSI risk stratification of Fowler was $15.2 \pm 3.8$ for the microbial sealant group and $15.5 \pm 4.0$ for the control group which was statistic not significant different $(\mathrm{p}=0.513)$. The resulting predicted SSI risk was $6.4 \%$ for the microbial sealant group and $6.4 \%$ for the control group.

\section{Patient characteristics}

Characteristics of patients receiving microbial sealant pre- treatment $(n=159)$ and controls $(n=132)$ are shown in (Table 1). The mean age of the patient-cohort was $68.6 \pm 10.9$ years (range, 26 to 89 years). In the microbial sealant group there were significantly more patients suffering from diabetes $(44.0 \%$ vs. $32.6 \%$, p =0.046) and highly significant increased number of patients suffered from carotid artery disease $(19.5 \%$ vs. $9.8 \%, \mathrm{p}=0.022)$ were more common among patients receiving microbial sealant pretreatment than in controls (Table 1). In both groups more than $40 \%$ suffered pre-operatively an acute myocardial infarction.

Surgical characteristic showed no differences within both groups on the priority of the procedure performance. In both groups more than $30 \%$ of the patients underwent an emergency procedure. The number of patients undergoing coronary bypass surgery were similar presented in both groups respectively $66.7 \%$ in the microbial sealant group and $58.3 \%$ in the control group ( $\mathrm{p}=0.143$ ). The number of anatomizes in both groups were also similar $2.2 \pm 0.9$ and $2.2 \pm 0.8$ in the microbial versus control group $(\mathrm{p}=1.000)$. Surgical details of the surgical procedures are shown in table 2 . There were statistically significant

Table 1: Pre-, peri-, and postoperative characteristics of patients and surgery. Data are $\mathrm{n}(\%)$ unless otherwise indicated.

\begin{tabular}{|c|c|c|c|}
\hline & $\begin{array}{l}\text { Microbial skin } \\
\text { sealant group } \\
\quad(n=159)\end{array}$ & $\begin{array}{l}\text { Control } \\
\text { group } \\
(n=132)\end{array}$ & $p$-value \\
\hline Age (years), mean \pm SD & $68.3 \pm 7.7$ & $69.0 \pm 8.6$ & 0.465 \\
\hline \multicolumn{4}{|l|}{ Gender } \\
\hline Male & $107(67.3)$ & $88(66.7)$ & \\
\hline Female & $52(32.7)$ & $44(33.3)$ & \\
\hline Hyperlipidaemia & $129(81.1)$ & $117(88.6)$ & 0.078 \\
\hline Arterial hypertension & $157(98.7)$ & $131(99.2)$ & 0.674 \\
\hline COPD & $28(17.6)$ & $34(25.8)$ & 0.091 \\
\hline Diabetes mellitus & $70(44.0)$ & $43(32.6)$ & 0.046 \\
\hline Peripheral artery disease & $40(25.2)$ & $33(25.0)$ & 1.000 \\
\hline Carotid artery disease & $31(19.5)$ & $13(9.8)$ & 0.022 \\
\hline Cardiovascular accident & $22(13.8)$ & $15(11.4)$ & 0.528 \\
\hline Renal failure & $37(23.3)$ & $35(26.5)$ & 0.523 \\
\hline LV ejection fraction, mean \pm SD & $42.4 \pm 14.8$ & $42.3 \pm 14.3$ & 0.954 \\
\hline Congestive heart failure & $71(44.7)$ & $49(37.1)$ & 0.194 \\
\hline Acute myocardial infarction & $69(43.4)$ & $55(41.7)$ & 0.766 \\
\hline \multicolumn{4}{|l|}{ Priority of procedure } \\
\hline Elective & $101(63.5)$ & $85(64.4)$ & 0.877 \\
\hline Urgent/emergency & $58(36.5)$ & $47(35.6)$ & \\
\hline \multicolumn{4}{|l|}{ Perfusion time } \\
\hline$<100 \mathrm{~min}$ & $95(59.7)$ & $75(56.8)$ & 0.614 \\
\hline$\geq 100 \mathrm{~min}$ & $64(40.3)$ & 57 (43.2) & \\
\hline
\end{tabular}

COPD, chronic obstructive pulmonary disease; LV, left ventricular; SD, standard deviation

Table 2: Details of surgical procedure.

\begin{tabular}{|c|c|c|c|}
\hline Variable & $\begin{array}{c}\text { microbial sealant } \\
\text { group }(\mathbf{n = 1 5 9 )} \mathbf{n} ; \%\end{array}$ & $\begin{array}{c}\text { control } \\
\text { group }(\mathbf{n = 1 3 2 )} \mathbf{n} ; \%\end{array}$ & -value \\
\hline Type of surgery & & & \\
\hline CABG & $50(31.4)$ & $35(26.5)$ & 0.357 \\
\hline Valve procedure & $22(13.8)$ & $38(28.8)$ & 0.002 \\
\hline Other single procedures & $9(5.7)$ & $5(3.8)$ & 0.457 \\
\hline CABG + valve procedure & $41(25.8)$ & $31(23.5)$ & 0.651 \\
\hline $\begin{array}{c}\text { Other combined proce- } \\
\text { dures }\end{array}$ & $37(23.3)$ & $23(17.4)$ & 0.220 \\
\hline Reoperation & & & \\
\hline CABG & $10(7.5)$ & $15(9.1)$ & 0.214 \\
\hline Valve procedure & $14(10.7)$ & $9(5.3)$ & 0.532 \\
\hline
\end{tabular}

Abbreviations: CABG; coronary artery bypass grafting 
more valve procedures performed in the control groups compared with the microbial sealant group $(28.8 \%$ vs. $13.8 \%$; $\mathrm{p}=0.002)$. Total concomitant procedures, however were more common performed in the control group compared with the microbial sealant group (88 patients vs. 54 patients, $\mathrm{p}=0.014)$.

\section{Incidence of SSI}

At the clinical end point of the study, SSI was recorded for $2.5 \%$ $(n=4)$ of patients in the microbial sealant group compared with $7.6 \%(\mathrm{n}=10)$ in the control group, which was a statistical significant reduction ( $\mathrm{p}=0.045$ ) (Figure 1). Moreover, there was a reduction of over $50 \%$ of SSI in the microbial sealant treated group compared with the predicted SSI risk based on patient's characteristics noticed which was $6.4 \%$. Microbiological examination showed that all patients were free of MRSA at screening. The microbial group showed 4 patients with SSI, including MSSA $(\mathrm{n}=1)$, MRSA $(\mathrm{n}=1)$, Staph. epidermidis $(\mathrm{n}=1)$ and Enterobacter cloacae $(\mathrm{n}=1)$. In the control group there were MSSA ( $\mathrm{n}=1)$, MRSA ( $\mathrm{n}=1)$, Staph. epidermidis $(\mathrm{n}=5)$, Pseudomonas aeruginosa $(\mathrm{n}=2)$ and Enterococcus faecalis $(\mathrm{n}=1)$.

\section{Discussion}

Surgical site infections are the most common hospital acquired infection for patients after surgery which has a morbidity and mortality. The incidence for SSI is depending on the co-morbidity of the patient. Some risk factors can be reduced or optimized, depending if elective surgery is performed. On the other hand surgeons have also the possibility to optimize the operative condition. It has been reported that off-pump coronary bypass surgery can reduce SSI. Sedrakyan et al. [22] showed in a meta-analyzes that wound infections could be reduced by $48 \%$ at the same risk as compared with on-pump surgery (RR, 0.52; 95\% CI, 0.37 to 0.74). Risk difference analyzes showed 40 SSI prevented per 1000 coronary bypass surgeries with an off-pump approach. Other studies showed the used mammary artery during coronary bypass surgery have superior patency rates of $>90 \%$ up to 15 years of follow-up [23]. Therefore it is preferred to use the mammary artery if needed both; however, the disadvantage is the reduction of blood supply of the sternum. Therefore a study of Peterson et al. [24] suggested to prepare the mammary artery skeletonized and not as a pedicle. This study showed the reduction of deep SSI in skeletonized mammary artery harvesting were less likely to develop superficial or

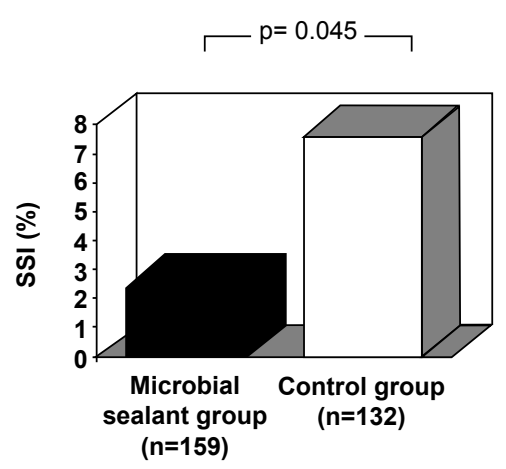

Figure 1: Incidence of surgical site infection (SSI) in patients undergoing coronary artery bypass graft surgery who were treated with a microbial sealant group compared with the control group. The incidence of SSI was statistically significantly lower in the microbial sealant group than in the control group $(2.5 \%$ vs. $7.6 \%, p=0.045$ ) deep sternal wound infection compared with pedicle harvesting $(5.1 \%$ vs. $22.2 \%$; $\mathrm{p}=0.03$ ).

The incidence of SSI during cardiac surgery accords also to the specific procedure which needs to be performed. Lepelletier et al. [25] studied this influence and showed different SSI risk for patients undergoing coronary artery bypass surgery and valve surgery, respectively $3.9 \%$ versus $1.6 \%$. Multivariate analyzes showed that coronary artery bypass grafting with the use of mammary artery was an independent risk factor associated with SSI. This study showed a statistically significant lower rate on patients with valvular procedures in the microbial sealant group compared with the control group, respectively $13.8 \%$ and $28.8 \%(\mathrm{p}=0.002)$. Therefore the patients of the microbial sealant group were from the interpretative variable at a high risk to develop SSI. Although the inclusion criteria in this study showed similar risk for SSI, which was developed for coronary bypass surgery patients, this was not recognized in this predictor score.

Sharony et al. [26] showed by performing a partial sternotomy compared with standard full sternotomy also a reduction of mediastinitis respectively, $(0 / 160$ vs. $8 / 337 ; p=0.05)$. Due to these surgical technique modifications it was possible to reduce SSI. The main source of microbes responsible for SSI is the endogenous flora, which can contaminate the surgical site [7,27]. Therefore new skin tools are investigated to reduce the surgical wound contamination by the endogenous skin flora. In this study we showed in high risk patients to develop SSI a microbial sealant which allows the transient and residual flora no longer to contaminate the surgical site. Although these patients had a high risk to develop a SSI, by including this microbial sealant there was a reduction of up to $70 \%$ of SSI in a similar patient population operated at the same hospital with a comparable risk profile. In another study performed by all surgeons of our institute including more than 3,200 patients there were high significant reduction of superficial SSI and mediastinitis seen during follow-up and over years [28].

Waldow et al. [29] studied in a single-centre investigation using two prospective registries to evaluate the prophylactic effect of an antimicrobial sealant on the incidence of mediastinitis. This study however has several limitations as pointed out previously [30]. First of all the title is misleading and incorrect since they found a difference between the microbial sealant and control group for development of SSI, respectively $2.3 \%$ and $3.2 \%$. This is statistically not significant however these are different values per se. The study endpoint was 30 days, however CDC guidelines [21] recommend the use of 1 year in case of foreigner body implantation which is generally done in valve surgery or aortic surgery. The number of patients in this study which were only followed for 30 days, instead of 1 year, was almost $50 \%$ in both groups, respectively 232/502 in the control group and 238/496 in the microbial sealant group. Therefore the data of this study used at 30 days are not this final data for SSI. The number of mediastinitis in this unselect patient population was for both groups higher as expected in Germany which is today below $1.4 \%$ for full sternotomy [31] or 1.1\% [32] which is more than double in the study of Waldow. Patient characteristics show also that both patient populations are at lower risk, shown by the limited number of patients with female gender, limited body mass index, limited mammary artery use, especially both mammary arteries in only $2.6 \%$ of the patient population. The number of patients in these studies on SSI needs to be much higher to allow significant differences as well as the follow up time should be correct. Therefore the data of this study needs to be carefully studied and have limited impact.

A prospective, randomized, controlled clinical trial of Iyer et al. [33] used a microbial sealant treatment at the donor site of a patient. The 
Citation: Dohmen PM, Gabbieri D, Weymann A, Linneweber J, Geyer T, et al. (2013) The Impact of a Microbial Sealant to Reduce Surgical Site Infections in High Risk Cardiac Surgery Patients. J Medical Microbiol Diagnosis S4: 002. doi:10.4172/2161-0703.S4-002

other donor site of the same patient was the control. After 47 patients were reviewed, the study was stopped, since there was a significant reduction of SSI at the donor site with a microbial sealant $(1 / 47 ; 2.1 \%)$ in contrast with the control group $(12 / 47 ; 25.5 \%)(\mathrm{p}=0.001)$. This trial demonstrated a serious reduction of the SSI at the donor site, however was not used at the chest.

In conclusion, this study shows due to the use of a microbial skin sealant in cardiac surgery the rate of SSI can be significantly reduced.

\section{Limitation}

Limitations of this study is that this study was not a randomized multi-center study but more a "real world patient collection", which shows more about daily live situation. The use of patients by a single surgeon it was performed to decrease bias in the patient's collection, however there is of course another possibility by doing so to create new bias. Both patient groups were different in some characteristics; however the patients in the microbial sealant group were at any time at higher risk to develop SSI. Sufficient randomized studies are needed.

\section{References}

1. Brown IW Jr, Moor GF, Hummel BW, Marshall WG Jr, Collins JP (1996) Toward further reducing wound infections in cardiac operations. Ann Thorac Surg 62: 1783-1789.

2. Fry DE (2006) The surgical infection prevention project: Processes, outcomes, and future impact. Surgical Infections 7: S17-26.

3. Milano CA, Kesler K, Archibald N, Sexton DJ, Jones RH (1995) Mediastinitis after coronary artery bypass graft surgery. Risk factors and long-term survival. Circulation 92: 2245-2251.

4. Mekontso-Dessap A, Kirsch M, Brun-Buisson C, Loisance D (2001) Poststernotomy mediastinitis due to Staphylococcus aureus: comparison of methicillin-resistant and methicillin-susceptible cases. Clin Infect Dis 32: 877883.

5. Dohmen PM (2012) Economic burden of surgical site infections in cardiac surgery. J Med Microb Diagn 1:e120.

6. Dohmen PM (2008) Antibiotic resistance in common pathogens reinforces the need to minimise surgical site infections. J Hosp Infect 70: 15-20.

7. Dohmen PM (2006) Influence of skin flora and preventive measures on surgical site infection during cardiac surgery. Surg Infect (Larchmt) 7: S13-17.

8. Basaran M, Kafali E, Ugurlucan M, Kalko Y, Selimoglu O, et al. (2008) Cyanoacrylate gluing increases the effectiveness of systemic antimicrobial treatment in sternal infection: experimental study in a rodent model. Thorac Cardiovasc Surg 56: 28-31.

9. Dohmen PM, Gabbieri D, Weymann A, Linneweber J, Konertz W (2009) Reduction in surgical site infection in patients treated with microbial sealant prior to coronary artery bypass graft surgery: a case-control study. J Hosp Infect 72: $119-126$

10. Dohmen PM, Weymann A, Holinski S, Linneweber J, Geyer T, et al. (2011) Use of an antimicrobial skin sealant reduces surgical site infection in patients undergoing routine cardiac surgery. Surg Infect (Larchmt) 12: 475-481.

11. Horan TC, Gaynes RP, Martone WJ, Jarvis WJ, Emori TG (1992) CDC definitions of surgical-site infections, 1992: a modification of CDC definitions of surgical wound infections. Infect Control Hosp Epidemiol 13:606-608.

12. Harrington G, Russo P, Spelman D, Borrell S, Watson K, et al. (2004) Surgicalsite infection rates and risk factor analysis in coronary artery bypass graft surgery. Infect Control Hosp Epidemiol 25: 472-476.

13. Abboud CS, Wey SB, Baltar VT (2004) Risk factors for mediastinitis after cardiac surgery. Ann Thorac Surg 77: 676-683.

This article was originally published in a special issue, Molecular Mechanisms of Viruses handled by Editor(s). Dr. Joel Kenneth Weltmann, Alpert Brown University, USA; Dr. Sumathi Sankaran, University of California, USA
14. Kaye KS, Sloane R, Sexton DJ, Schmader KA (2006) Risk factors for surgical site infections in older people. J Am Geriatr Soc 54: 391-396.

15. Segers P, de Jong AP, Kloek JJ, Spanjaard L, de Mol BA (2006) Risk control of surgical site infection after cardiothoracic surgery. J Hosp Infect 62: 437-445.

16. McConkey SJ, L'Ecuyer PB, Murphy DM, Leet TL, Sundt TM, et al. (1999) Results of a comprehensive infection control program for reducing surgical-site infections in coronary artery bypass surgery. Infect Control Hosp Epidemiol 20: 533-538.

17. Russo PL, Spelman DW (2002) A new surgical-site infection risk index using risk factors identified by multivariate analysis for patients undergoing coronary artery bypass graft surgery. Infect Control Hosp Epidemiol 23: 372-376.

18. Fowler VG Jr, O'Brien SM, Muhlbaier LH, Corey GR, Ferguson TB, et al. (2005) Clinical predictors of major infections after cardiac surgery. Circulation 112: I358365 .

19. Gastmeier P, Sohr D, Schwab F, Behnke M, Zuschneid I, et al. (2008) Ten years of KISS: the most important requirements for success. J Hosp Infect 70: 11-16.

20. Dohmen PM, Konertz W (2007) A review of current strategies to reduce intraoperative bacterial contamination of surgical wounds. GMS Krankenhhyg Interdiszip 2: Doc38.

21. Mangram AJ, Horan TC, Pearson ML, Silver LC, Jarvis WR (1999) Guideline for Prevention of Surgical Site Infection, 1999. Centers for Disease Control and Prevention (CDC) Hospital Infection Control Practices Advisory Committee. Am J Infect Control 27: 97-132.

22. Sedrakyan A, Wu AW, Parashar A, Bass EB, Treasure T (2006) Off-pump surgery is associated with reduced occurrence of stroke and other morbidity as compared with traditional coronary artery bypass grafting: a meta-analysis of systematically reviewed trials. Stroke 37: 2759-2769.

23. Shah PJ, Durairaj M, Gordon I, Fuller J, Rosalion A, et al. (2004) Factors affecting patency of internal thoracic artery graft: clinical and angiographic study in 1434 symptomatic patients operated between 1982 and 2002. Eur J Cardiothorac Surg 26: 118-124.

24. Peterson MD, Borger MA, Rao V, Peniston CM, Feindel CM (2003) Skeletonization of bilateral internal thoracic artery grafts lowers the risk of sternal infection in patients with diabetes. J Thorac Cardiovasc Surg 126: 1314-1319.

25. Lepelletier D, Perron S, Bizouarn P, Caillon J, Drugeon H, et al. (2005) Surgicalsite infection after cardiac surgery: incidence, microbiology, and risk factors. Infect Control Hosp Epidemiol 26: 466-472.

26. Sharony R, Grossi EA, Saunders PC, Schwartz CF, Ursomanno P, et al. (2006) Minimally invasive reoperative isolated valve surgery: early and mid-term results. J Card Surg 21: 240-244

27. Malangoni MA, Cheadle WG, Dodson TF, Dohmen PM, Jones D, et al. (2006) New opportunities for reducing risk of surgical site infection. Roundtable discussion. Surg Infect (Larchmt) 7: S23-39.

28. Dohmen PM (2013) Impact of antimicrobial skin sealants on surgical site infections. Surg Infect (in press)

29. Waldow T, Szlapka M, Hensel J, Plötze K, Matschke K, et al. (2012) Skin sealan InteguSeal $\circledast$ has no impact on prevention of postoperative mediastinitis after cardiac surgery. J Hosp Infect 81: 278-282.

30. Dohmen PM (2012) Use of microbial sealant to prevent surgical site infections. J Hosp Infect 82: 302-303.

31. Gummert JF, Barten MJ, Hans C, Kluge M, Doll N, et al. (2002) Mediastinitis and cardiac surgery--an updated risk factor analysis in 10,373 consecutive adult patients. Thorac Cardiovasc Surg 50: 87-91.

32. Eklund AM, Lyytikäinen O, Klemets P, Huotari K, Anttila VJ, et al. (2006) Mediastinitis after more than 10,000 cardiac surgical procedures. Ann Thorac Surg 82: 1784-1789.

33. Iyer A, Gilfillan I, Thakur S, Sharma S (2011) Reduction of surgical site infection using a microbial sealant: a randomized trial. J Thorac Cardiovasc Surg 142 438-442. 